\title{
VARIAÇÃO NA CONCORDÂNCIA VERBAL DE TERCEIRA PESSOA DO PLURAL NA FALA DOS FLORIANOPOLITANOS NATIVOS NA COSTA DA LAGOA
}

\author{
VERBAL AGREEMENT VARIATION IN THIRD PERSON OF PLURAL IN THE \\ SPEECH OF DWELLERS FROM COSTA DA LAGOA IN THE CITY OF \\ FLORIANÓPOLIS
}

Lidiomar José Mascarello. Mestrando do Programa de Pós-Graduação em Linguística da UFSC

\begin{abstract}
Resumo
O presente artigo trata de uma breve investigação da variação na concordância verbal de terceira pessoa do plural na fala de florianopolitanos residentes na comunidade da Costa da Lagoa, situada a Leste da Ilha de Santa Catarina. Apoiados no referencial teórico da sociolinguística variacionista, analisamos fatores que podem condicionar a variação do fenômeno em questão. Os dados analisados são referentes a uma amostra de oito entrevistas, algumas do banco de dados do Projeto VARSUL (3) e outras (5) realizadas por alunos do programa de Pós-Graduação em Linguística, observando as mesmas condições de coleta do VARSUL. Verificamos que o fenômeno da variação da concordância verbal de terceira pessoa do plural está condicionado tanto por fatores linguísticos quanto por fatores sociais.
\end{abstract}

Palavras chave: Variação. Concordância verbal. Fatores linguísticos/sociais.

\begin{abstract}
This article is a brief research about the verbal agreement variation of third person of plural in the speech of dwellers from Costa da Lagoa in the city of Florianópolis, situated in the east part of the Island of Santa Catarina. Based on the theoretical framework of variationist sociolinguistics, we analyze factors that may condition the variation of the phenomenon researched. Data analyzed come from eight interviews, some from a data bank from VARSUL (3) and others (5) carried out by students from the graduate studies in linguistics, performed under identical conditions of data collection from Project VARSUL. We found out that the phenomenon of variation of verbal agreement of the third person of plural seems to occur due to linguistic factors as well as to social factors.
\end{abstract}

Keywords: Variation. Verbal agreement. Linguistic/social factors.

\section{INTRODUÇÃO}

Há alguns anos que sociolinguistas e dialetólogos realizam estudos sobre a variação da concordância verbal. Estudos esses motivados por preocupações diversas, mas que compartilham uma ideia comum, que pode ser assim formulada: a realidade linguística brasileira não é apenas variável e heterogênea, mas também é plural, na medida em que no Brasil, coexiste, ao lado de uma variedade culta, padrão, uma outra variedade dita não-padrão, popular, vernacular. Estudos sobre aplicação/não-aplicação da regra de 
concordância verbal no português não-padrão foram realizados por, entre outros, Lemle e Naro (1977), Naro (1981), Guy (1981), Bortoni-Ricardo (1981 e 1985), Assis (1988), Baxter e Lucchesi (1993), Mello (1996) (apud Monguilhott 2001). Na Região Sul, especificamente em Florianópolis, a primeira pesquisa realizada sobre variação da concordância verbal de terceira pessoa do plural foi a de Monguilhott (2001). Todos esses estudos foram baseados no pressuposto de que o português popular brasileiro, ou não-padrão, é aquela variedade mais utilizada por brasileiros do mundo rural ou do mundo urbano, analfabetos ou de baixo nível de escolarização e letramento. É sabido que todos possuímos e utilizamos o vernáculo, mas parece que no contexto descrito acima há uma maior manifestação da variação.

Poderíamos ampliar essa lista de pesquisadores e de trabalhos desenvolvidos nessa área, pois inúmeros estudos já foram realizados de norte a sul do país, apontando assim a importância e a relevância desse fenômeno em variação. Todos esses registros apontam com evidência e com bastante clareza que o fenômeno de variação na concordância verbal, longe de ser restrito a uma região ou classe social, se manifesta em toda comunidade de fala brasileira e é sistematicamente variável.

É nosso objetivo, aqui, descrever, ainda que de forma breve, o fenômeno de variação da concordância verbal de terceira pessoa do plural na fala de informantes florianopolitanos e analisar grupos de fatores linguísticos e sociais que podem influenciar essa variação. Mais especificamente, interessa-nos analisar a fala de indivíduos de descendência açoriana que nasceram, cresceram, trabalham e vivem na Costa da Lagoa - comunidade que mistura o urbano com o rural em uma região tombada pelo município de Florianópolis como Área de Preservação Cultural.

O artigo está organizado em três seções: a descrição da comunidade de fala; a metodologia; e a descrição e análise de dados de concordância variável, com resultados estatísticos referentes aos grupos de fatores considerados.

\section{DESCRIÇÃO DA COMUNIDADE DE FALA}

A Costa da Lagoa é considerada um dos últimos redutos da cultura açoriana e possui um núcleo de pescadores e rendeiras que ainda vivem como seus antepassados, além de uma forte cultura baseada em mitos, como o de que bruxas habitavam a região em tempos remotos. ${ }^{1}$

Com relevo acidentado, o único acesso por terra é através de caminhos que a ligam à Freguesia da Lagoa, passando pelo Canto dos Araçás; ao Saco Grande, passando pelas montanhas; e ao Ratones, também pelas montanhas, em sua parte mais baixa. É ao longo do caminho que leva à Freguesia que sempre se distribuíram as casas dos moradores e, atualmente, dos novos habitantes: os que buscam a calma da localidade. No percurso dos $5 \mathrm{~km}$ do caminho encontram-se pontes, escadarias, rampas e outras obras onde a engenharia dos antigos habitantes desenvolveu trabalhos que ainda hoje, à mercê das intempéries, estão servindo como única via de acesso terrestre à sede do Distrito da Lagoa. Outra forma de acesso à Costa são as embarcações, por exemplo, baleeiras que fazem a linha Freguesia-Costa e Parque do Rio Vermelho-Costa. A Costa

\footnotetext{
${ }^{1}$ http://pt.wikipedia.org/wiki/llha_de_Santa_Catarina
} 
da Lagoa é um núcleo comunitário desmembrado da comunidade da Lagoa da Conceição. $^{2}$

A colonização da Lagoa começou no século XVIII, com as armações de pesca Depois as planícies e encostas passaram a ser ocupadas por lavouras em terras comunais. A partir de 1748 iniciou-se oficialmente a distribuição de terras a colonos açorianos na Ilha. O ano de 1750 é tido como o início do núcleo do que hoje é a Lagoa. Com a chegada dos açorianos, o uso comunal das terras deu lugar à posse, com fragmentação das áreas dominadas pelos donos de barcos e redes de pesca. Surgem os núcleos urbanos. A Barra da Lagoa foi o primeiro núcleo, depois o Centrinho da Lagoa da Conceição. A economia da Barra era voltada à pesca marítima e à agricultura. $\mathrm{O}$ Centrinho volta-se à agricultura e à pesca lagunar. Mais tarde dá-se a urbanização da Costa da Lagoa.

A Lagoa foi o primeiro distrito administrativo do Desterro que, em 1894, passa a ser chamado de Florianópolis. Por 200 anos, a comunidade da Lagoa manteve-se relativamente isolada, embora sempre tenha tido trocas com outras comunidades da Ilha.

A Costa da Lagoa também é fruto desse processo de transformação, mas por ser um local de mais difícil acesso parece que parou um pouco no tempo e consegue manter ainda alguns traços mais conservadores; é uma típica colônia de pescadores que ainda preserva algumas construções que lembram o desenvolvimento do local, como alguns engenhos, casarões e sobrados. O artesanato da Costa da Lagoa e na Lagoa da Conceição (principalmente a renda de bilro e a rede de pesca) é uma das referências culturais, que está ligado diretamente com a maneira que vivia a comunidade no início de sua colonização. Baseada na agricultura e pesca, limitava-se basicamente à arte dos trançados. Entre suas principais manifestações estão a renda-de-bilro e a rede de pesca e, de acordo com um antigo ditado português: "Onde há rede, há renda". Com relação aos trançados, há também a rede de taboa (já desaparecida), e os artefatos de cipó, bambu e vime.

No quadro a seguir podemos observar com mais detalhes como se constitui a população da comunidade da Costa da Lagoa, segundo dados estatísticos oferecidos pela prefeitura municipal de Florianópolis.

QUADRO 1: Distribuição da população da Costa da Lagoa ${ }^{3}$

\begin{tabular}{|c|c|c|c|c|c|c|c|c|c|}
\hline \multicolumn{3}{|c|}{ Residentes } & \multicolumn{3}{|c|}{ Homens residentes } & \multicolumn{4}{|c|}{ Mulheres residentes } \\
\hline \multicolumn{2}{|c|}{778} & & \multicolumn{3}{|c|}{399} & \multicolumn{4}{|c|}{379} \\
\hline \multicolumn{10}{|c|}{ Homens Residentes por idade (anos) } \\
\hline Anos & $0 \mathrm{a} 4$ & 0 a 5 & $1 \mathrm{a} 4$ & 1 a 5 & 5 a 9 & 10 a 19 & 20 a 49 & 50 a 59 & + de 60 \\
\hline 6 & 27 & 30 & 21 & 27 & 36 & 71 & 223 & 21 & 21 \\
\hline \multicolumn{10}{|c|}{ Mulheres Residentes por idade (anos) } \\
\hline Anos & $0 \mathrm{a} 4$ & 0 a 5 & $1 \mathrm{a} 4$ & 1 a 5 & 5 a 9 & 10 a 19 & 20 a 49 & 50 a 59 & + de 60 \\
\hline 6 & 27 & 33 & 21 & 27 & 30 & 64 & 197 & 25 & 36 \\
\hline
\end{tabular}

\footnotetext{
${ }^{2}$ http://www.radarsul.com.br/florianopolis/historia.asp

3 Disponível em: http://www.pmf.sc.gov.br/saude/unidades_saude/populacao/ulst_2008.php, acesso em 17de maio de 09.
} 


\section{METODOLOGIA}

Os dados analisados são provenientes de entrevistas realizadas com moradores residentes na Costa da Lagoa, em ambiente mais natural possível (casa ou trabalho do entrevistado). Para este artigo foram selecionadas oito entrevistas, sendo três realizadas por Isabel de O. Monguilhott, em 2006, e cinco realizadas por alunos do Programa de Pós-Graduação em Linguística da UFSC, em 2009. As entrevistas foram gravadas com mini gravador digital e adicionadas ao banco de dados do Projeto VARSUL/SC.

Os informantes estão assim distribuídos em relação à estratificação social: quanto à escolaridade - quatro informantes com Ensino Fundamental incompleto, com no máximo seis anos de escolaridade, e quatro informantes com Ensino Superior completo; quanto à faixa etária - dois dos informantes menos escolarizados são jovens adultos na faixa etária de 20 a 30 anos, e dois são adultos com idade entre 40 e 60 anos; o mesmo foi considerado para os indivíduos mais escolarizados. Por se tratar de um trabalho de pesquisa breve, serão considerados apenas os cinquenta primeiros dados de cada informante.

Uma das hipóteses aqui investigadas é que indivíduos com maior tempo de escolarização apresentam um índice menor de variação e não concordância verbal, e sujeitos com menor tempo de escolarização apresentam um índice maior de variação e não concordância verbal em sua fala. Outra hipótese de natureza social é que pessoas com mais idade tendem a fazer mais concordância verbal, enquanto pessoas mais jovens tendem a fazer menos concordância verbal.

Quanto às hipóteses de natureza linguística, propomo-nos a testar os principais grupos de fatores já evidenciados por diversos pesquisadores como os mais importantes condicionadores da variação da concordância verbal: a ordem do sujeito e a saliência fônica. A hipótese é que o sujeito posposto leva à ocorrência de menos concordância, enquanto o sujeito anteposto, à ocorrência de mais concordância. Adicionalmente, quanto mais saliente a flexão, maior é a marcação de concordância e quanto menos saliente, menor é a marcação de concordância. Outra hipótese diz respeito à animacidade: sujeito mais animado propicia mais concordância verbal do que sujeito menos animado.

\section{DESCRIÇÃO E ANÁLISE DOS RESULTADOS}

Os resultados dos estudos de Lemle e Naro (1977) indicam que o uso da regra de concordância verbal pelos informantes relaciona-se diretamente com o grau de saliência fônica entre a forma singular e plural dos verbos e a posição do sujeito. Em relação ao grupo de fatores 'saliência fônica', os autores verificaram que a sílaba não acentuada desfavorece a concordância, enquanto a sílaba acentuada favorece a presença da marca flexional de concordância. Para a variável posicional, a posição em que o sujeito está imediatamente antes do verbo favoreceu a concordância no verbo, opondo-se à posição em que o sujeito está posposto ao verbo bem como à distância do sujeito em relação ao verbo. Monguilhott (2001), por sua vez, verificou que os traços do sujeito, mais 
animado ou menos animado, também interferem na realização ou não da concordância ${ }^{4}$. As mesmas variáveis linguísticas são controladas e consideradas para este trabalho: saliência fônica, posição do sujeito e animacidade.

Quanto às variáveis sociais, foram controladas a escolaridade e a idade. Na tabela 1, vemos a distribuição geral das primeiras cinquenta ocorrências da variável em estudo, por informante.

TABELA 1: Distribuição dos informantes de acordo com a escolaridade e a idade, e número de dados obtidos por informante

\begin{tabular}{c|c|c|c|c|c}
\hline Informantes & Escolaridade & Idade & $\begin{array}{c}\text { Concordância } \\
\text { Total } / \boldsymbol{\%}\end{array}$ & $\begin{array}{c}\text { Não Concordância } \\
\text { Total / \% }\end{array}$ & Total \\
\hline $\mathbf{0 1}$ & SUPERIOR & 29 & $37 / 74$ & $13 / 26$ & 50 \\
\hline $\mathbf{0 1}$ & SUPERIOR & 24 & $46 / 92$ & $04 / 08$ & 50 \\
\hline $\mathbf{0 1}$ & SUPERIOR & 47 & $36 / 72$ & $14 / 28$ & 50 \\
\hline $\mathbf{0 1}$ & SUPERIOR & 40 & $37 / 74$ & $13 / 26$ & 50 \\
\hline $\mathbf{0 1}$ & FUNDAMENTAL & 29 & $30 / 60$ & $20 / 40$ & 50 \\
\hline $\mathbf{0 1}$ & FUNDAMENTAL & 30 & $38 / 76$ & $12 / 24$ & 50 \\
\hline $\mathbf{0 1}$ & FUNDAMENTAL & 56 & $23 / 46$ & $27 / 54$ & 50 \\
\hline $\mathbf{0 1}$ & FUNDAMENTAL & 54 & $25 / 50$ & $25 / 50$ & 50 \\
\hline Total & 08 & & $272 / 68$ & $128 / 32$ & $400 / 100 \%$ \\
\hline
\end{tabular}

Ao observarmos os resultados gerais na tabela acima, podemos perceber que $68 \%$ do total dos dados apresentam concordância e que 32\% dos dados são de não concordância verbal. Ao detalharmos a análise, conforme os postulados da teoria variacionista, percebemos que há diversos fatores interligados que propiciam a variação linguística. É o que veremos nas subseções a seguir.

\subsection{Resultados dos grupos de fatores sociais}

Apresentamos inicialmente os resultados obtidos para a variável 'idade’ e, na sequência, para a variável 'escolaridade'. O gráfico 1 evidencia os percentuais de concordância e de não concordância verbal, de acordo com as duas faixas etárias controladas na amostra analisada.

\footnotetext{
${ }^{4}$ Monguillott (2001) observou o emparelhamento entre animacidade e preenchimento do sujeito: quando ocorre a combinação de sujeito menos animado em sintagma pleno aumenta a possibilidade de não ocorrer concordância, enquanto o sujeito preenchido por pronome e/ou de caráter mais animado favorece a concordância entre o sujeito e o verbo na terceira pessoa do plural.
} 


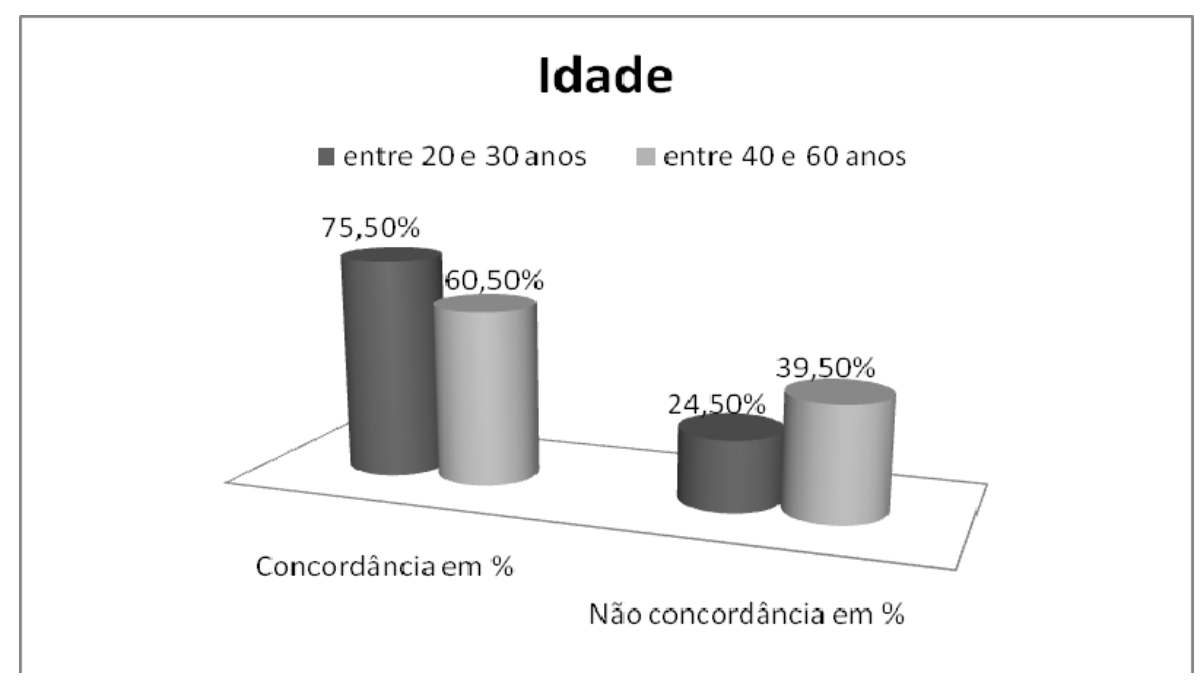

GRÁFICO 1: Frequência de concordância verbal, segundo a variável 'idade’

Como podemos observar nos dados, ocorre um percentual maior de concordância entre os indivíduos da faixa etária de 20 a 30 anos e uma maior variação e menor concordância nos indivíduos de idade entre 40 e 60 anos, não ratificando, portanto, a nossa hipótese inicial de que pessoas mais velhas fariam maior concordância verbal. Uma das hipóteses interpretativas levantadas para esse resultado é de que os indivíduos mais jovens estão em contato com um número maior de pessoas que vêm de fora, não nativos, e esse contato leva os jovens nativos a perceberem que há diferenças na fala. Encontramos declarações como: "eles olham já falam: essa aí é manezinha” (04FNEJ) ${ }^{5}$, "parece que a gente não fala as palavras certas elas não saem," "eles trazem novidade" $(02 \mathrm{FEJ})^{6}$. Esses comentários denotam uma percepção da variação e um desejo de imitar o outro, uma vez que se considera a fala desse outro mais bonita e mais correta. Por outro lado, os indivíduos com mais idade não revelam, ou não expressam, esse tipo de preocupação.

Além disso, os indivíduos mais jovens estão enfrentando a concorrência do mercado de trabalho, o que provavelmente os leva a uma maior observação da fala dos indivíduos que não são nativos, mas que passaram a viver em sua comunidade e a disputar com eles o mesmo espaço. Durante as entrevistas constatou-se que houve uma mudança significativa dos hábitos e dos trabalhos dos nativos dessa comunidade, por exemplo, os mais jovens saem pra estudar fora e deixam de executar tarefas ligadas à pesca e à renda de bilro, atividades estas tidas como básicas e elementares dos integrantes dessa comunidade. Essa constante interação com integrantes de outras comunidades de fala faz com que se percebam as diferenças e com isso as pessoas tentam diminuí-las; mas, como a concordância verbal e variação de não concordância são registradas em todas as regiões e comunidades brasileiras, também se manifestam nessa comunidade.

Podemos concluir, concordando com Monguilhott (2001), que as pessoas mais pressionadas pela idade profissionalmente produtiva usam mais as formas prestigiadas.

No Gráfico 2, visualizamos os resultados para a variável ‘escolaridade’.

\footnotetext{
${ }^{5}$ Informante número 04, sexo feminino, menos escolarizada, jovem.

${ }^{6}$ Informante número 02, sexo feminino, mais escolarizada, jovem.
} 


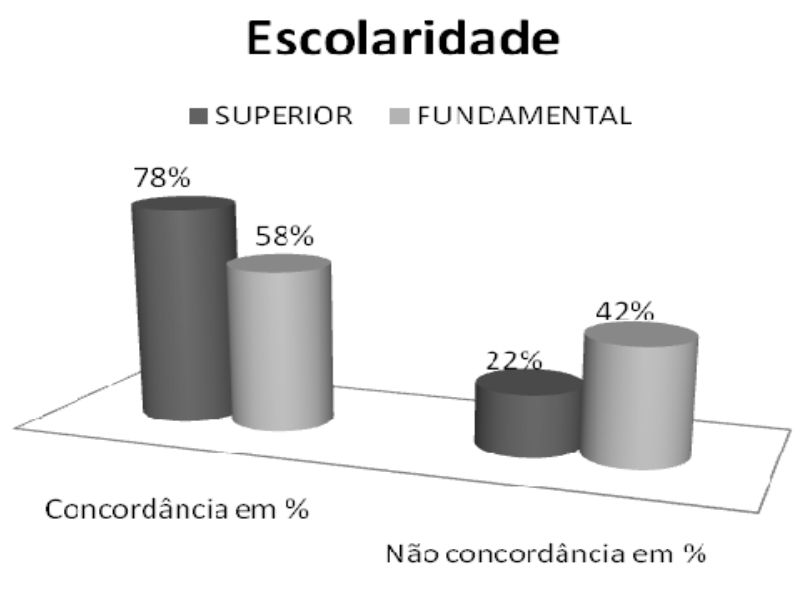

GRÁFICO 2: Frequência de concordância verbal, segundo a variável 'escolaridade’

Dentre os grupos de fatores sociais analisados, os anos de escolarização mostraram-se bastante relevantes atestando que quanto mais escolarizados são os informantes menor é a variação e a não concordância verbal, ratificando o que o próprio Labov e outros pesquisadores constataram (1978, apud MONGUILHOTT 2001).

Os dados nos mostram que o ensino sistematizado da escola cumpre seu papel de reforçar a variante mais prestigiada da língua e que quanto maior o tempo passado na escola, maior é o uso da variante mais prestigiada pelas classes sociais que detêm a organização de empreendimentos por onde circula o maior capital de giro, capital econômico. Houve manifestações nas entrevistas que revelam esse conflito: "As características da fala, os mais antigos falam, têm mais coisas, acho que eles falam errado" ${ }^{7}$. Esses mais antigos na realidade eram pais, avós, familiares que não tiveram oportunidade de estudar.

\subsection{Resultados dos grupos de fatores linguísticos}

Os resultados apresentados a seguir correspondem às variáveis 'saliência fônica', ‘posição do sujeito’ e ‘animacidade’, respectivamente.

O grupo de fatores referente à saliência fônica foi estabelecido em função de critérios preestabelecidos por Naro (1981), e trata da presença ou ausência de acento na desinência e da quantidade de material fônico que diferencia a forma singular da forma plural. A partir desses critérios, estabelecemos dois níveis de saliência, os mesmos de Monguilhott (2001) - uma vez que parte dos dados analisados é coincidente -, e em cada nível três categorias, realçando a diferença fônica da relação singular/plural, os quais podem ser observados abaixo:

Nível 1- oposição não acentuada:

a) Não envolve mudança na qualidade da vogal na forma plural (ex.: consegue/conseguem)

\footnotetext{
${ }^{7}$ Informante 02: sexo feminino, mais escolarizado (nível superior), menos de 30 anos (24 anos).
} 
Todas as crianças da comunidade conseguem estudar na escola. (01FEJ29)

Eles montam negócio não consegue continuá, não consegue pagá aluguel (07FEV47)

b) Envolve mudança na qualidade da vogal na forma plural (ex.: era/eram)

Meu pai e meus tios eram pescadores (02FEJ24)

Era minhas melhores amiga (02FEJ24)

c) Envolvendo acréscimo de segmentos na forma plural (ex.: quer/querem)

Todos aqueles que saíram querem voltar. (06FNV56)

Os menino num qué sabe. (07FEV47)

Nível 2 - oposição acentuada:

a) Envolve apenas mudança na qualidade da vogal na forma plural.(ex.: vai/vão)

Outras pessoa vai modificando a comunidade (01FEJ29)

As pessoas que vêm de fora vão colaborando pra que a gente vá melhorando (01FEJ29)

b) Envolve acréscimo de segmentos sem mudanças vocálicas na forma plural. (ex.: foi/foram)

As dificuldade aqui sempre foi o deslocamento e a energia elétrica. (03MNJ30)

Meus pais foram viajar, (02FEJ24).

c) Envolve acréscimos de segmentos e mudanças diversas na forma plural (ex.: é/são)

No verão é muitos turista (04FNJ30)

Agora os menino são amigo de mulhé, antes não, (05FNV54)

Seguindo os mesmos passos de Monguilhott (2001), agrupamos e apresentamos no gráfico 3 apenas dois fatores: 'mais saliência' (correspondendo à reunião dos fatores no nível 2 descrito acima) e 'menos saliência' (equivalendo aos três fatores do nível 1 acima). 


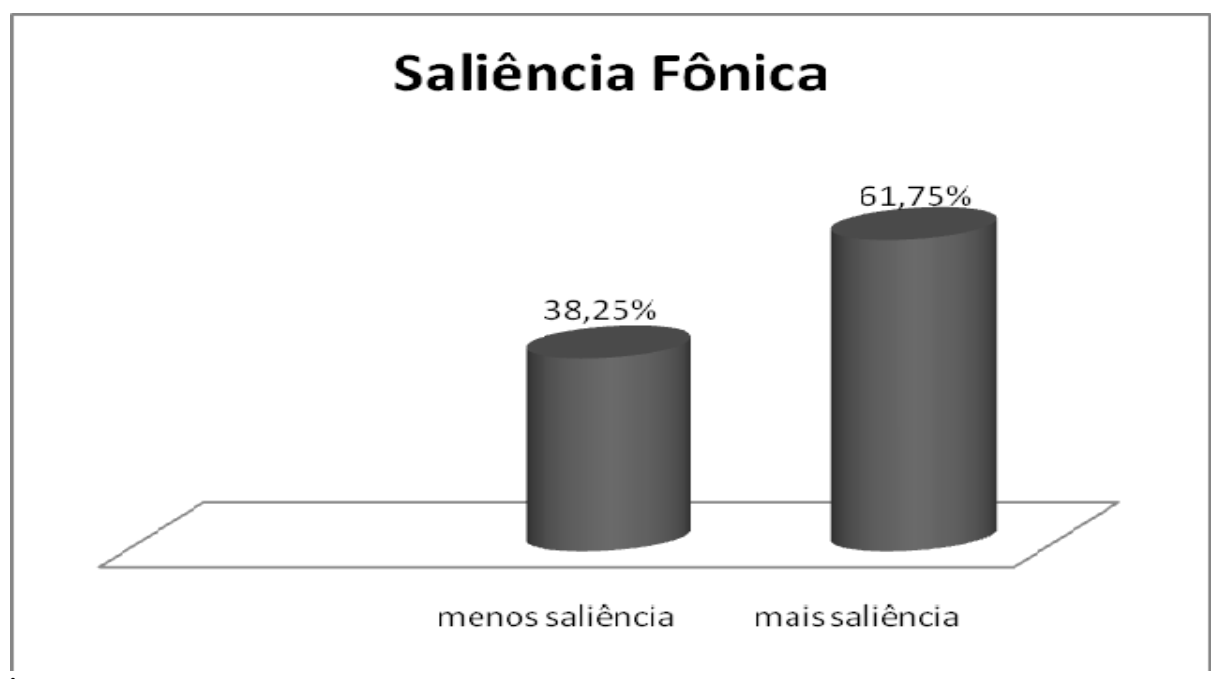

GRÁFICO 3 Frequência de concordância verbal, segundo a variável 'saliência fônica'

Como podemos observar no gráfico 3, quanto maior a saliência fônica (ex.: "Meus pais, meus avós é daqui” (é/são) (01FEJ29) ${ }^{8}$, menor é a variação e a não concordância, já que o percentual de concordância verbal é de $61,75 \%$ nesse caso. Em contrapartida, quanto menor a saliência fônica (ex.: "as lerda, como eles diziam” (dizia/diziam) (01FEJ29)", maior é a variação e a não concordância, com um percentual de 38,25\% associado a esse fator. Tais resultados corroboram os de Monguilhott (2001) e atestam nossa hipótese inicial.

Vários estudos realizados por Lemle e Naro (1977), Naro (1981), Scherre e Naro (1997) apontaram que as formas mais salientes tendem a ser mais marcadas do que as menos salientes, isto é, os falantes percebem que alguma coisa parece soar estranho quando as oposições são mais significativas e com isso a ocorrência explícita de marcação do plural é mais frequente.

Outro grupo de fatores a ser levado em consideração em nossa análise é a posição do sujeito em relação ao verbo. Os resultados, apresentados no gráfico 4, atestam nossa hipótese: a aplicação da regra de concordância é maior quando o sujeito está anteposto ao verbo, como em:

“Já tem bastante sujeitos da minha família que saíram [...] Tenho muitas primas que casaram [...] Elas foram morar pra fora [...] As pessoas estão voltando pra cá para educar os filhos.” (01FEJ29)

Por outro lado, quando o sujeito está posposto ao verbo, ocorre uma tendência de menor concordância, como em:

"Depois vinhero as festa junina [...] Quem pagou o pato foi os nativos o governo esqueceu das coisas que a gente tá precisando aqui." (03MNJ35)

\footnotetext{
${ }^{8}$ Informante número 01, sexo feminino, mais escolarizada, jovem.

${ }^{9}$ Informante número 01, sexo feminino, mais escolarizada, jovem.
} 


\section{Posição do Sujeito}

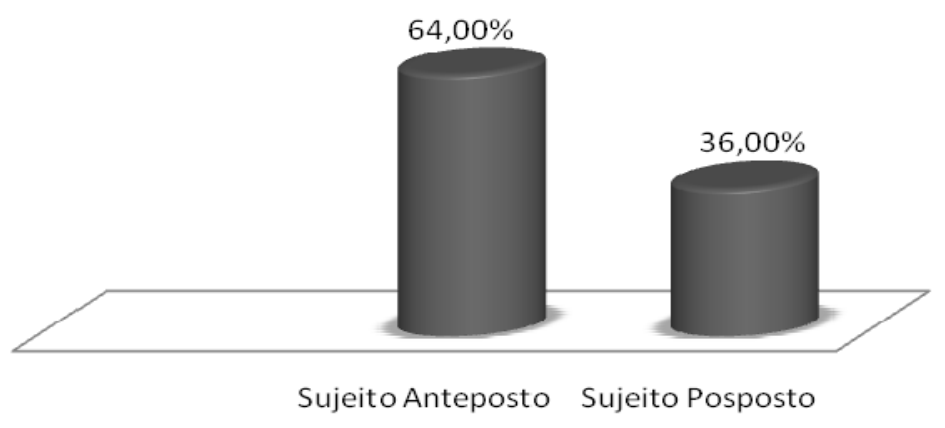

GRÁFICO 4 Frequência de concordância verbal, segundo a variável ‘posição do sujeito’

Os resultados obtidos aqui - 64\% de concordância com sujeito anteposto e 36\% com sujeito posposto ao verbo - confirmam aqueles evidenciados em outros estudos já realizados observando a mesma variável. Segundo Monguilhott (2001), quando o sujeito está posposto ao verbo há uma tendência de ser encarado como objeto pelo falante e por isso a regra de concordância deixa de ser aplicada, já que passa a não ser considerado como sujeito da sentença. Uma explicação a esse fenômeno vem de Belletti (1988, apud MONGUILHOTT), que propõe que o sintagma nominal posposto a verbos, principalmente verbos inacusativos, pode ser marcado com partitivo sempre que o objeto receber uma leitura parcial ou indefinida, e segundo Monguilhott (2001) o verbo atribuidor desse Caso não precisa no português brasileiro apresentar marcas de concordância, uma vez que a flexão não tem função de atribuir Caso nominativo ao sintagma nominal.

Um outro grupo de fatores que se mostrou significativo foi a animacidade e a não animicidade do sujeito. Nossa hipótese inicial - quanto menos animado for o sujeito maior a tendência de variação e não concordância, e vice-versa - foi atestada, conforme mostra o resultado do gráfico 5 .

A animacidade do sujeito está relacionada ao traço semântico mais humano e menos humano, conforme mostram os exemplos, respectivamente:

“As crianças antes corriam na areia, hoje não dá pra fazer isso. As coisas melhoraram, meus irmãos é que ajudaram a família depois que o pai morreu. Meus irmãos também pescavam” (06FEV47)

"As mesma tradição de antes, só as plantação que não tem mais, as plantação deu lugar pras casa dos filho” (05FNV54). 


\section{Animacidade do Sujeito}

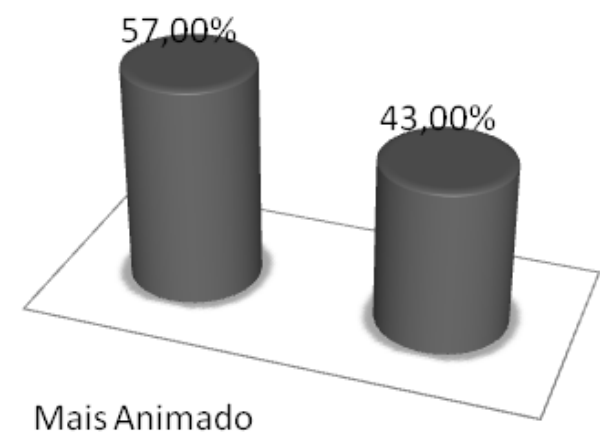

Menos

Animado

GRÁFICO 5: Frequência de concordância verbal, segundo variável 'animacidade do sujeito'

Se o sujeito faz referência a um ser humano, ou a um ser animado, maior é o uso da regra de concordância verbal (57\%) e quando o sujeito não se trata de ser humano ou o traço de animacidade é menor, é menor também a aplicação dessa mesma regra (43\%).

Esses resultados referentes às variáveis linguísticas caminham na mesma direção dos resultados apresentados por Lemle e Naro (1997), Naro e Scherre (1999, 2000, no prelo) - precursores do estudo da concordância verbal no Brasil -, assim como por Monguilhott (2001), entre outros.

\section{CONSIDERAÇÕES FINAIS}

Podemos observar, através dos resultados aqui apresentados, que tanto fatores sociais quanto fatores linguísticos interferem na realização ou não da regra de concordância verbal de terceira pessoa do plural. Embora este não tenha sido um estudo exaustivo, os resultados apontam na mesma direção de trabalhos realizados sobre o português falado em outras regiões do Brasil, no campo da sociolinguística variacionista. Em relação às interferências internas ao sistema linguístico, atestamos que ambientes foneticamente mais salientes, sintagmas nominais-sujeitos antepostos ao verbo e o traço semântico mais animado do sujeito estão fortemente correlacionados à presença de marca flexional de número-pessoa no verbo. Em contrapartida, ambientes menos salientes, sintagmas nominais pospostos e traço menos humano do sujeito são fatores favoráveis à não concordância verbal.

Constatamos, com a análise de dados coletados na comunidade da Costa da Lagoa em comparação com resultados de outros estudos, que realmente a variação não é privilégio de um grupo social, de uma comunidade mais isolada, ou de uma região específica do nosso país, uma vez que as ocorrências variáveis de (não) concordância verbal registradas em pesquisas realizadas de Norte ao Sul do país caminham na mesma direção e apontam para os mesmos fatores, tanto sociais quanto linguísticos, que limitam ou favorecem a realização de uma ou de outra variante da variável 'concordância verbal de terceira pessoa do plural'. 


\section{REFERÊNCIAS}

LEMLE, Miriam \& NARO, Anthony J. Competências básicas do Português. Relatório Final apresentado às instituições patrocinadoras Fundação Movimento Brasileiro (MOBRAL) e Fundação FORD, Rio, 1977.

MONGUILHOTT, Isabel de Oliveira e Silva. Variação na concordância verbal naterceira pessoa do plural na fala de florianopolitanos. Florianópolis. 2001. Dissertação de Mestrado em Lingüística. UFSC - Universidade Federal de Santa Catarina.

Um estudo da concordância verbal de terceira pessoa em Florianópolis. In: VANDERSEN, Paulino. Variação e mudança no português falado na região Sul.

Pelotas: EDUCAT, p. 189-215, 2002.

NARO, Anthony J. \& LEMLE, Miriam. Syntatic diffusion. Ciência e Cultura, v. 29, $n^{\circ} 3$ pp. 259-68, 1977

NARO, Anthony J. \& SCHERRE, Maria Marta Pereira. Variação e Mudança Lingüística: fluxos e contrafluxos na comunidade de fala. In: Cadernos Estudos Lingüísticos Campinas (20): 9-16, Jan/Jun. 1991.

Sobre as origens do português popular do Brasil. DELTA, Vol. 9, $\mathrm{N}^{\circ}$ Especial, p. 443 - 454, 1993.

Sobre o efeito do princípio da saliência na concordância verbal na fala moderna, na escrita antiga e na escrita moderna. In: MOURA, Denilda (org.) Os múltipos usos da língua. Maceió: EDUFAL, pp 26-37. 1999a.

A influência de variáveis escalares na concordância verbal. In: A cor das Letras. Revista do Departamento de Letras e Artes da Universidade Estadual de Feira de Santana. Nº 3, dezembro. Bahia: Feira de Santana, p. 17-34, 1999b.

NARO, Anthony J. \& VOTRE, Sebastião Josué. Emergência da sintaxe como efeito discursivo. In: Relatório Final do Projeto Subsídio sociolingüístico à educação.

UFRJ. CNPq, 1986.

IBGE Censo Demográfico $2000 \quad$ (Estimativa 2008) http://www.pmf.sc.gov.br/saude/unidades_saude/populacao/ulst_2008.php. Atualizado em dezembro de 2008.

RODRIGUES Angela C. Souza. Concordância Verbal, Sociolingüística E História Do Português Brasileiro - Universidade de São Paulo. 2004. Publicado no Fórum Lingüístico, Florianópolis, v. 4, n.1 (115-145), julho de 2004 